\section{Michigan Technological

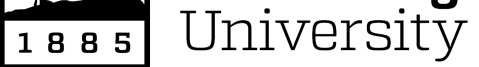

Michigan Technological University Digital Commons @ Michigan Tech

\title{
Installation of a Variable-angle Spectrometer System for Monitoring Diffuse and Global Solar Radiation
}

O. Ormachea

Universidad Privada Boliviana

\author{
A. Abrahamse \\ Universidad Privada Boliviana \\ N. Tolavi \\ Universidad Privada Boliviana \\ O. Urquidi \\ Universidad Privada Boliviana \\ Joshua M. Pearce \\ Michigan Technological University
}

See next page for additional authors

Follow this and additional works at: https://digitalcommons.mtu.edu/materials_fp

\section{Recommended Citation}

Ormachea, O., Abrahamse, A., Tolavi, N., Romero, F., Urquidi, O., Pearce, Joshua M., \& Andrews, R. "Installation of a variable-angle spectrometer system for monitoring diffuse and global solar radiation," C3 - Proceedings of SPIE/ Manuel Filipe P. C. Martins Costa, Editor, Proc. SPIE 8785, 87850 (2013). http://digitalcommons.mtu.edu/materials_fp/53 
Authors

O. Ormachea, A. Abrahamse, N. Tolavi, O. Urquidi, Joshua M. Pearce, and R. Andrews 


\title{
Installation of a variable-angle spectrometer system for monitoring diffuse and global solar radiation
}

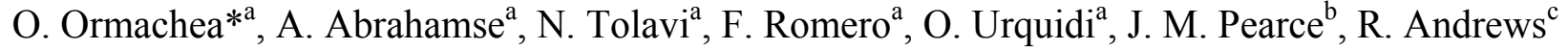 \\ ${ }^{a}$ Centro de Investigaciones Opticas, Universidad Privada Boliviana, 3967 Km. 6.5 Av. Capitan \\ Ustariz, Cochabamba, Bolivia \\ b \\ Department of Materials Science \& Engineering and Department of Electrical \& Computer \\ Engineering, Michigan Technological University, 601 M\&M Building, 1400 Townsend Drive, \\ Houghton, MI 49931-1295, USA \\ 'Queen's Applied Sustainability Research Group, Queen's University, 60 Union St. Kingston, \\ ON K7L 3N6, Canada
}

\begin{abstract}
We report on the design and installation of a spectrometer system for monitoring solar radiation in Cochabamba, Bolivia. Both the light intensity and the spectral distribution affect the power produced by a photovoltaic device. Local variations in the solar spectrum (especially compared to the AM1.5 standard) may have important implications for device optimization and energy yield estimation.

The spectrometer system, based on an Ocean Optics USB4000 (300-900nm) spectrometer, was designed to increase functionality. Typically systems only record the global horizontal radiation. Our system moves a fiber-optic cable $0-90$ degrees and takes measurements in 9 degree increments. Additionally, a shadow band allows measurement of the diffuse component of the radiation at each position. The electronic controls utilize an Arduino UNO microcontroller to synchronizes the movement of two PAP bipolar (stepper) motors with the activation of the spectrometer via an external trigger. The spectrometer was factory calibrated for wavelength and calibrated for absolute irradiance using a Sellarnet SL1-Cal light source.
\end{abstract}

We present preliminary results from data taken March-June, 2013, and comment on implications for PV devices in Cochabamba.

Keywords: Spectral radiation, Spectral variation, Spectral effects, Photovoltaic energy yields, Open source hardware

\section{INTRODUCTION}

The sun radiates energy in all directions, with a spectrum close to that of a black body at $6000 \mathrm{~K}^{1}$, due to the tilt of the earth and its path variable in different seasons, the radiation at a specific location can vary over a high percentage. Many factors, including the same atmosphere, which absorbs $16 \%$ of the total radiation that reaches the earth before going through this ${ }^{2}$, clouds and aerosols, among others, cause variations in the radiation received at the surface of the earth.

Precise knowledge of the incident solar radiation on the earth's surface is of great importance for a variety of scientific applications from agriculture to the study of global warming ${ }^{3-7}$.

*oormachea@upb.edu; phone 591 44268287; fax 591 44268288; upb.edu

8th Iberoamerican Optics Meeting and 11th Latin American Meeting on Optics, Lasers, and Applications,

edited by Manuel Filipe P. C. Martins Costa, Proc. of SPIE Vol. 8785, 87850M

(C) 2013 SPIE $\cdot$ CCC code: $0277-786 X / 13 / \$ 18 \cdot$ doi: $10.1117 / 12.2025480$ 
In particular, for applications of solar electric energy production, information on the "solar resource" is very important. The electrical solar power stations (thermal) need to predict the electrical energy produced with a margin of error of less than $5 \%$, the photovoltaic power stations and micro-generation systems connected to the network, require accurate data on the variability of the solar resource.

The intensity of solar radiation, its variability and also the solar spectrum affects the strength of power in electrical generation by solar systems ${ }^{8-10}$.

The standard spectrum AM 1.5, used in the optimization of crystalline silicon photovoltaic modules (currently the most common material for photovoltaic panels) mainly reflects the characteristics of the solar spectrum at mid-latitudes and altitudes near sea level, these spectral characteristics correspond to many regions of Europe and the United States ${ }^{11}$. New photovoltaic materials (thin films, multijunction cells, etc.) Have different quantum efficiencies, as these materials are becoming commercially viable, it is important to study the solar spectrum in the different parts of the world ${ }^{12}$.

The solar spectrum in Bolivia (a country characterized by its equatorial latitude and high in many parts of the country) has influence on efficiency of solar systems, so it is important to characterize the solar spectrum in this region with incident radiation characteristics highly variable.

Currently in Bolivia has a deficit in information about the solar resource, in terms of data of the spectral distribution of the radiation in the country, the information is even more nascent. The only source of data on solar radiation and accessible to the public, are satellite data from NASA Surface Meteorology and Solar Energy. Although these data may be useful for pre-feasibility studies, the accuracy of satellite data are highly variable ${ }^{13,14}$.

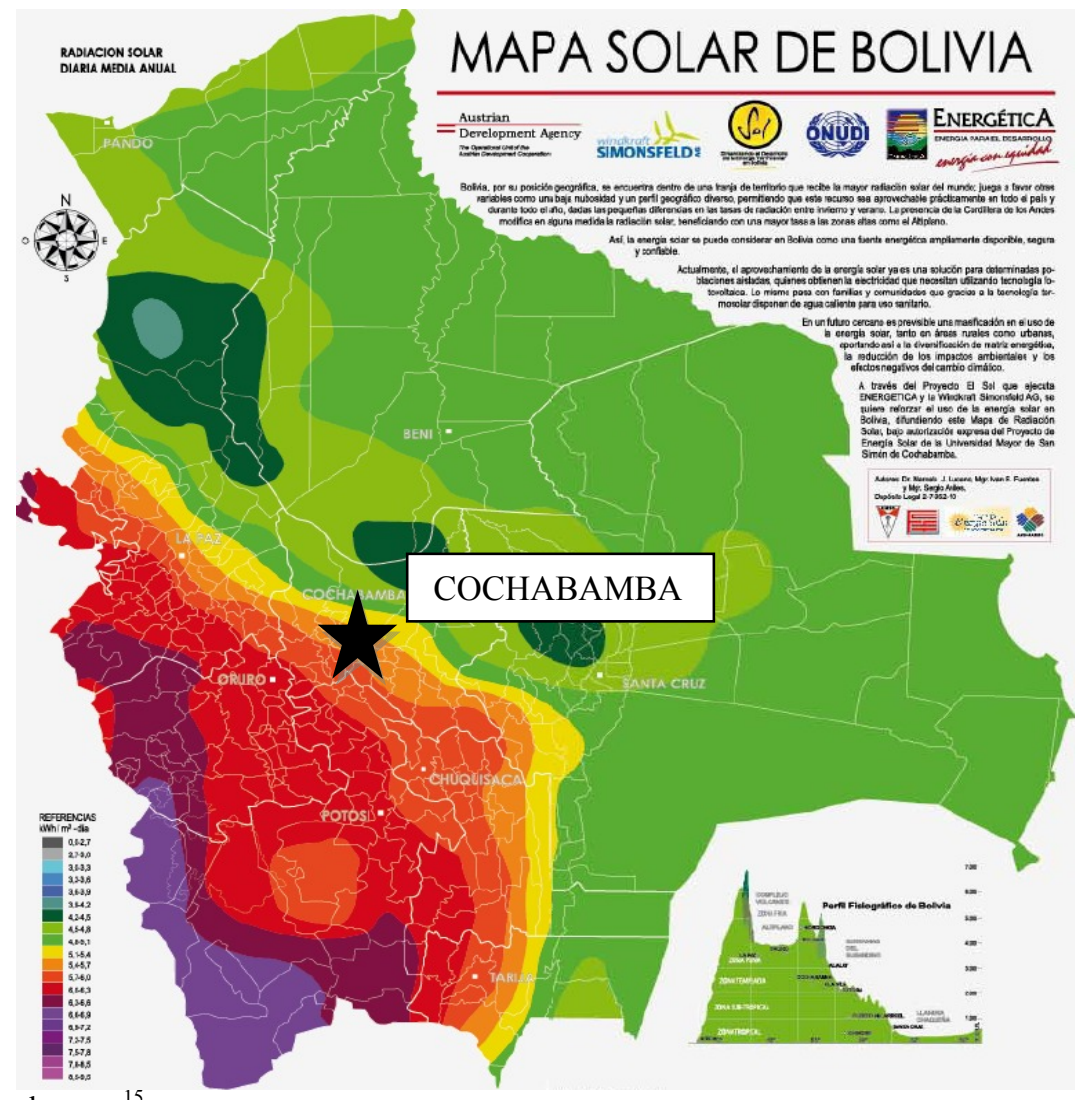

Figure 1. Bolivian solar map ${ }^{15}$

These data are processed to a network of $40 \mathrm{X} 40 \mathrm{~km}$, distances are not fine enough to take into account micro-climatic variations ${ }^{16}$, also the temporal resolution of these data are averages of periods of three hours, a resolution that does not allow variability studies of the efficiency of photovoltaic systems ${ }^{17}$.

Bolivia currently has a solar map (see Figure 1) which averages extensive regions of $1^{\circ}$ latitude by $1^{\circ}$ longitude based on NASA satellite images and an interpolation method $^{15}$, to estimate the radiation received in terms of the months of the 
year, where the accuracy of this map has not been verified by a long-term period. In general, the accuracy of satellite data is highly variable and in many cases over $10 \%{ }^{18}$.

Therefore, the existence of a network of solar radiation measurement is essential for sizing photovoltaic systems, thermal systems and ultra violet radiation activated systems. As mentioned above, the incident radiation on the earth's surface is a function of height, Bolivia has territories are practically at sea level and altitudes of over 6000 meters, having a very important portion habited land that is on the $4000 \mathrm{~m}$, the Bolivian highlands. However, systems for monitoring and measurement of solar radiation are expensive (high precision systems have costs above $\$ 30,000$ U.S., also do not incorporate elements to measure the solar spectrum.

In this research, was built and designed a system for measuring solar radiation based on a wide spectrum spectrometer. Monitoring of solar radiation with this instrument, allow us to study solar effects in Cochabamba for the best prediction of the efficiency of solar systems, the optimization and adjustment of the existing solar map, that being based on satellite photographs can only be used as an estimate of solar radiation.

It is proposed to install a monitoring network, based on the constructed system (relatively inexpensive), installed in different parts of the country. The current USB spectrometers are of small size and relatively low cost compared to conventional monitoring systems based on Pyranometers, the proposed prototypes not only measures directly global solar radiation, but diffuse, very important parameters for the design of photovoltaic cells and thermal systems mainly.

\section{CONSTRUCTION OF A SOLAR RADIATION MEASURING SYSTEM}

The photovoltaic panels are installed generally northward inclined at a fixed angle, it is important to measure the spectrum at different angles of incidence, also the albedo of the soil surface in addition to solar radiation, influences on the incident spectrum and varies in proportion to the "view factor". To consider these effects, the spectrometer measures taken regularly at various angles with respect to the horizontal.

The solar radiation measuring system built, comprises a commercial Ocean Optics spectrometer USB4000, adjusted to a quartz fiber diameter of 1000 microns, whose end contains a spell or CR2 Stellarnet cosine receptor and a coupling for measuring radiation such as the sun, a CR2 Stellarnet AP with $10 \%$ opening. The end of the optical fiber is attached to a bar at a certain distance, which will be driven by the first stepper motor in increments of 9 degrees in a space of 0 to 90 degrees, to take a measurement at each site.

Additionally, the system was designed to allow measurement of the spectrum of diffuse radiation. A second motor is attached to a shade band of determined ratio and wide to shade the sensor, depending on the day and time of year. A total of 20 measurements will be taken every hour, ten direct radiation at different angles and ten diffuse radiation, also at different angles. The control and synchronization of the system is governed by an Arduino UNO microcontroller, which is responsible for moving both engines using the Adafruit Motor Shield controller board, is needed additionally to perform the calculation of the sun position to shade the sensor and synchronize and manage data capture to the spectrometer. To keep track of the time and date, data needed to calculate the position of the sun, an RTC (real time clock) was connected to Arduino, which by having a separate battery, keeps track of the exact time and date even if the system is not energized. We used the latest version of the watch, called Chronodot v2.1. The spectrometer is directly and permanently connected to a computer in which data are stored by date for later analysis.

\subsection{Mechanical Structure}

The mechanical structure of the system is constituted of pieces of aluminum profile $30 \times 60 \mathrm{~mm}$ joined by bolts of different diameters and depths to give a support system consisting of two engines, the support of the quartz fiber (see Figure 2a) and an airtight case for holding the spectrometer and the microcontroller (see Figure 2b). The aluminum is a relatively inexpensive and available in the city of Cochabamba.

The mechanical structure height is $2 \mathrm{~m}$ (see Figure $2 \mathrm{c}$ ). The basic elements of the structure are both engine mounts, one fixed to a Teflon rod holding the quartz fiber that connects to the spectrometer and the other holding the shade band (semicircle for producing shadow to the fiber and allow the measurement of scattered radiation). For calculating the diameter and the width of the shade band, an equivalence between the diameter and radius of a radiometer certificate was used. The result was a radius of $13.5 \mathrm{~cm}$ and a width of $2.5 \mathrm{~cm}$. Depending on these parameters, the metal structure was designed, the system support and the box containing the spectrometer and the microcontroller depend on available space and wiring structure. 


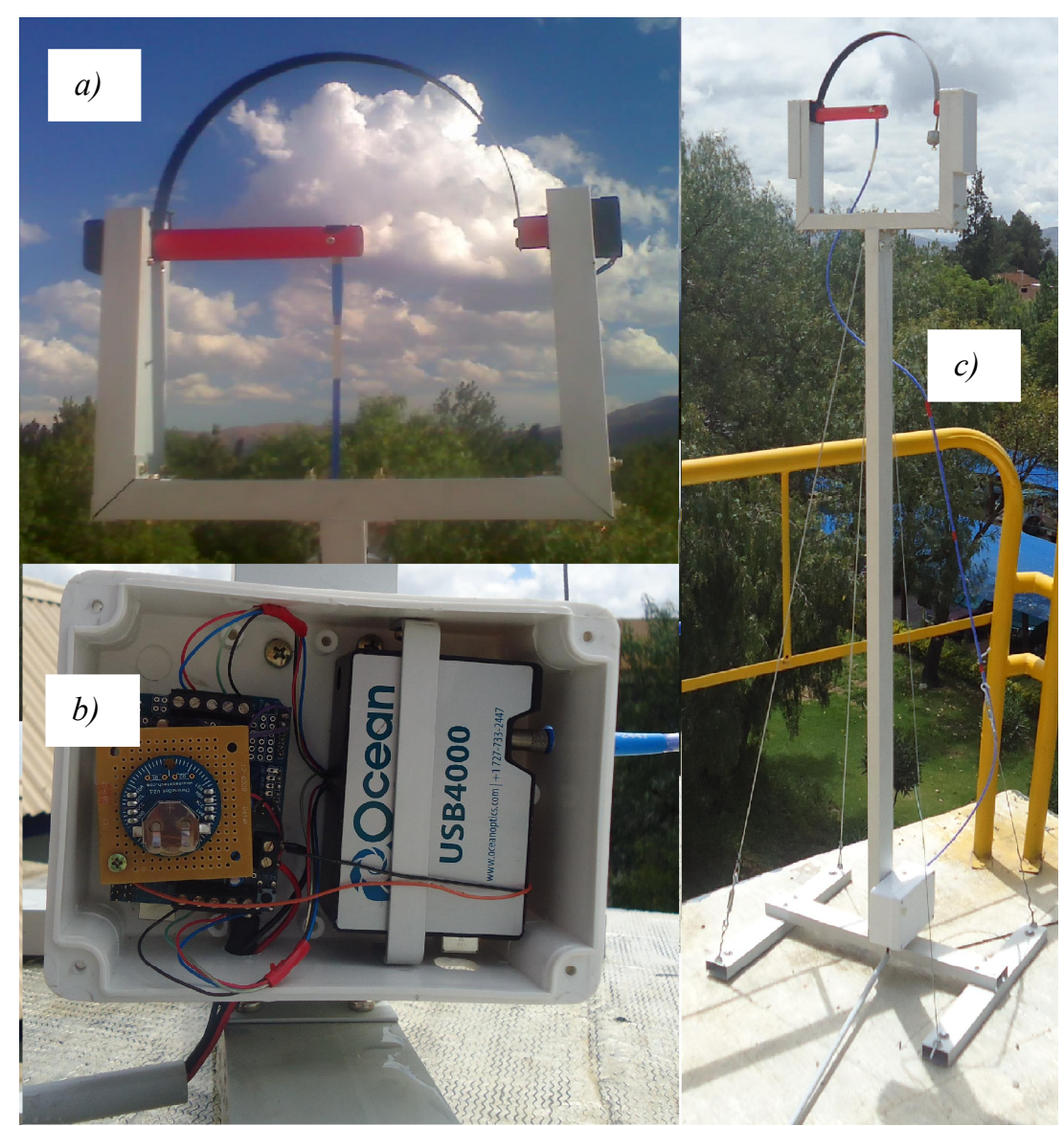

Figure 2. Engine mechanical structure and fiber (a), sealed case (b), installed mechanical structure (c)

Also were considered in the design details for the structure to withstand climate change, so the engines were covered with aluminum plates and sealed with silicone, as also the inlet and outlet of the sealed case cables were sealed with silicone to prevent water leaks, additionally guy wires were added to the four corners of the support to prevent movement in the event of strong winds. Finally the structure was bolted to the floor on the roof of one of the rooms of the Universidad Privada Boliviana, to ensure fixation in orientation, with the sensor and the shadow band pointing to magnetic north, at an angle of 8 degrees west, being the latitude $17.4^{\circ}$ South and longitude $66.2^{\circ}$ West, calculation for the city of Cochabamba.

\subsection{Electronics and Control}

Because the system is governed by the Arduino microcontroller, the main program is written in $\mathrm{C}$ language The Arduino UNO is a microcontroller that has 6 analog inputs / outputs and 13 digital inputs / outputs, which can be programmed for the required purpose. Communication with the computer to burn the programs is done by connecting a USB port, previously drivers installed. About the energy required, the Arduino UNO can work with the energy of the computer, or connecting a 9VDC external source.

It took into account three crucial aspects on the program development: the movement of both motors, data of the position of the sun at noon each day, and the RTC to take an exact account of time.

The electromechanical structure of the system is within the aluminum frame and the box sealed entirely except for the motor power supply cables and connection with the computer.

Both engines are bipolar, step by step, four-wire. To set them up, it had to extend the four imputs to tight box and connect to the engine controller board attached to the Arduino UNO, which has a 9V supply for the microcontroller and $\mathrm{a}+5 \mathrm{~V}$ and GND for engines. 


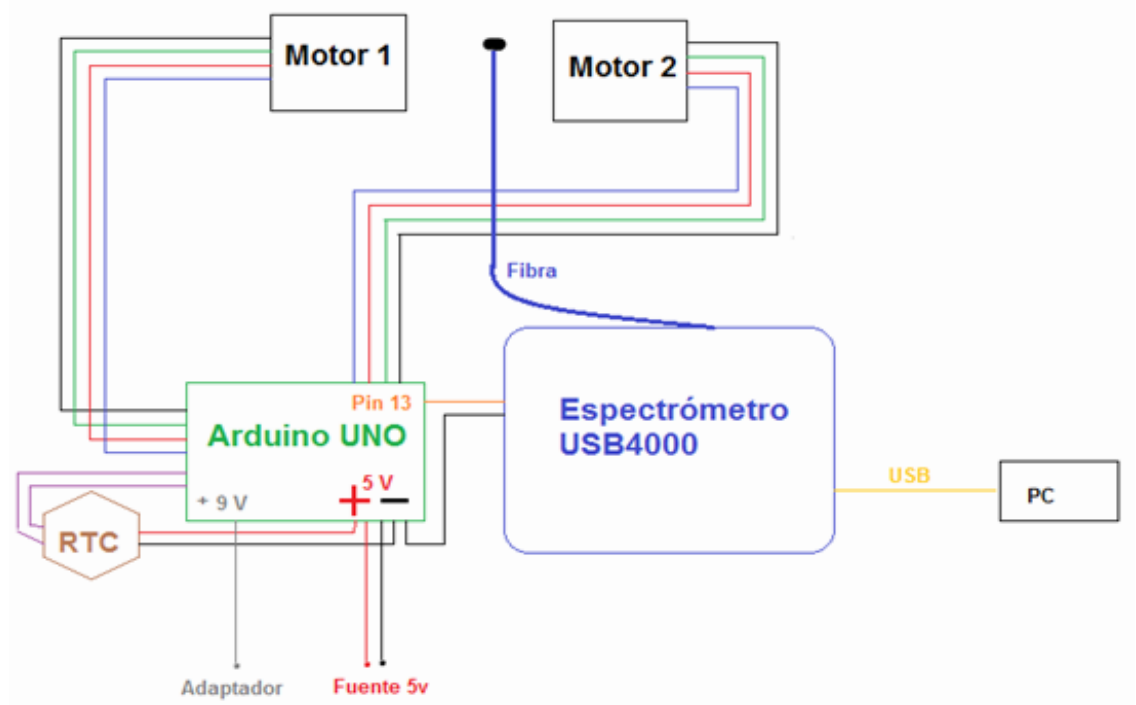

Figure 3. Diagram System Connection electromechanical

We must take into account that the response curve of the engines to get enough torque for them to be able to move the fiber and the shadow band. Figure 3 shows the connection of motors according to their function in the pins of the engine controller board. It was found experimentally that the current needed to achieve sufficient torque is at least $1.5 \mathrm{~A}$.

Furthermore, the digital pin Arduino \# 13 is connected to the spectrometer in its pin \# 7, which sends a pulse to obtain data capture, and GND connection at pin \# 6 of the spectrometer.

The analog ports \# 4 and \# 5 of the Arduino are connected to the RTC to its ports SDA and SDC, in charge of time data, respectively. In addition, the RTC is also powered by $+5 \mathrm{~V}$ and GND connection, to prevent independent battery is spent very quickly.

\section{PRELIMINARY RESULTS}

Ocean Optics spectrometer USB4000 was factory certified in regard to calibration function of wavelength in a range of 200-900 nm, the instrument in terms of intensity units shows arbitrary units "counts". In order to obtain data on intensities (absolute values), you need to calibrate the system, this is provided for this type of instruments, which should be used SpectraSuite software, connected to the spectrometer in Absolute Irradiance mode, whose units are $\mu \mathrm{W} /(\mathrm{cm} 2 *$ $\mathrm{nm}$ ) on the vertical axis and wavelength $\mathrm{nm}$ on the horizontal axis.

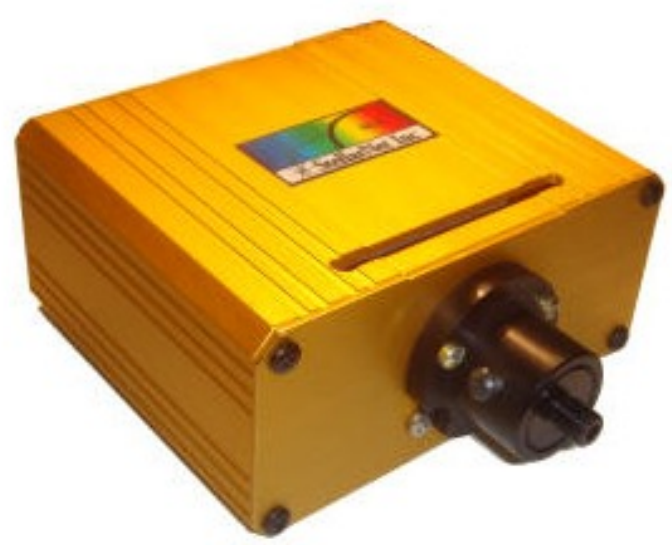

Figure 4. Sellarnet SL1-Cal calibrated light source 
We used a light source SL1-Cal " Sellarnet " light source (Figure 4), which came factory calibrated, whose light source is halogen and has a range of 300-1100 $\mathrm{nm}$. The reference file of this item was shipped by the manufacturer.

The reference file Lmp is used to compare the curve obtained with the spectrometer in "ua" units by nm and the actual radiation at $\mu \mathrm{W} / \mathrm{cm}^{2}$ per $\mathrm{nm}$, through this operation, data is created in Excel format, importing a text file of two columns, the first is the wavelength in $\mathrm{nm}$ and the second the irradiance in $\mu \mathrm{W} / \mathrm{cm}^{2}$.

To run the calibration was performed a task: Converting data references file SL1CAL-12121307 Inserted from W/m ${ }^{2}$ to $\mu \mathrm{W} / \mathrm{cm}^{2}$, made the previous step, we continued by inserting the cosine corrector in the sensor compartment of the calibrated light source

Later with the spectrometer connected to a computer, within SpectraSuite software in File $>$ New $>$ New AbsoluteIrradianceMeasurement, data collection source was chosen and we proceeded to load the reference spectra with and without light, because of the cosine corrector, we have a $1 / 4$ inch opening, ie 6350 microns in diameter with $180^{\circ}$ field of view. In Figure 5 shows the response curve Irradiance mode Absolute calibrated spectrometer and in which can be seen intensity values.

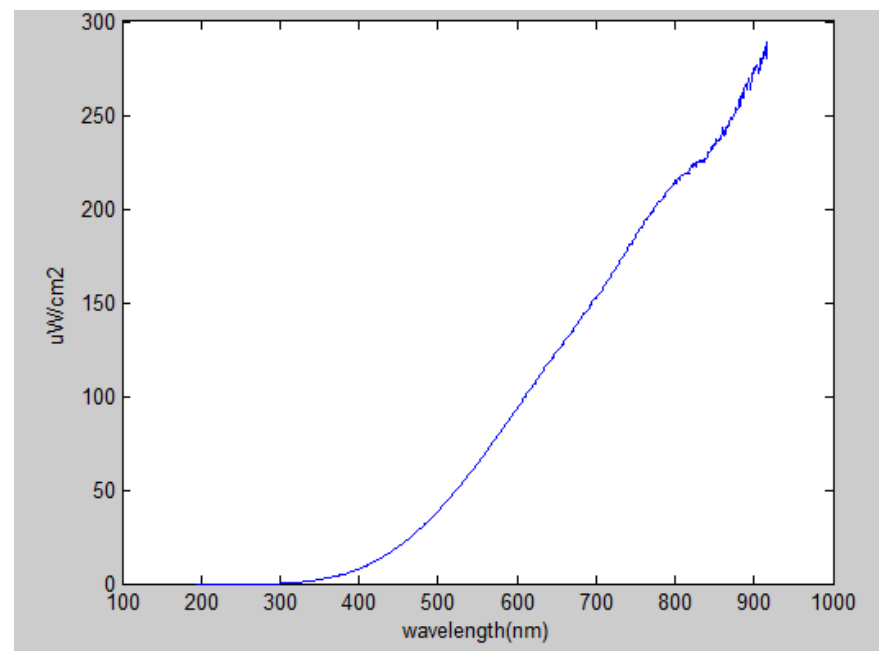

Figure 5. USB 4000 spectrometer calibrated absolute irradiance as a function of wavelength

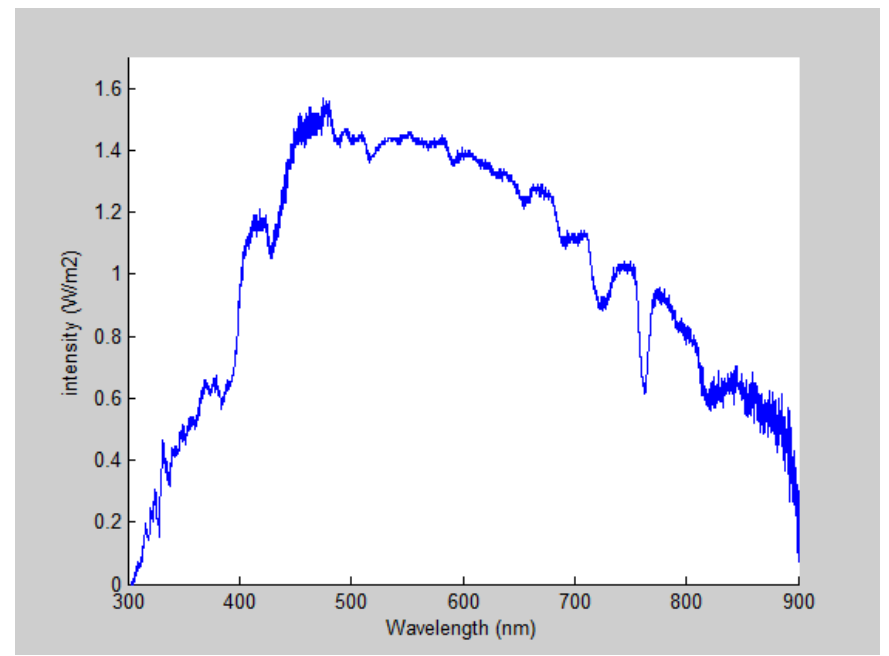

Figure 6. Intensity radiation as a function of wavelength

The measurements made with the system calibrated in function of both wave longitude as absolute irradiance as shown in Figure 6, where integrating the area under the curve gives the value of solar intensity for the indicated spectral range 
$300-900 \mathrm{~nm}$, this value is $599.2 \mathrm{~W} / \mathrm{m} 2$, obtained in 10.04.2013, which is within the ranges of solar radiation in Cochabamba at this time of year. In this type of measurements obtained, can be obtained the value corresponding to the intensity integrated in any time of year specified a certain time of day, but additionally it can be obtained solar intensity as a function of wavelength information, if what is need is to measure the UVA region, it can be obtained from the data.

\section{CONCLUSIONS}

A solar radiation monitoring system has been built and developed based on a spectrometer of wide specter "ocean Optics USB4000 (300-900 $\mathrm{nm})$ ". The spectrometer was factory calibrated for wavelength and calibrated for absolute irradiance using a Stellarnet SL1-Cal light source.

The system was installed in the city of Cochabamba Bolivia, that can be found at a height of 2574 mamsl, where its currently obtaining data of direct and diffuse radiation in function of wave length in an automatized manner. Preliminary findings of direct solar intensity in a range of $300-900 \mathrm{~nm}$ are presented, that at first glance the intensity values generated match the data obtained by other means of measurement

\section{REFERENCES}

[1] Tonda, J., [El oro solar y otras fuentes de energía], Fondo de cultura económica, México, (2003).

[2] Rösemann, R., [Solar Radiation Measurement], (2004).

[3] Duffie, J. A. and Beckman, W. A., [Solar engineering of thermal processes], Jhon Wiley \& Sons Inc., (2006).

[4] Dunlop, J. P., [Photovoltaic Systems], American Technical Publishers Inc, (2010).

[5] Messenger, R. A. and Ventre, J., [Photovoltaic Systems], CRC Press, Florida, (2004).

[6] Escalera, R., Ormachea, O., "Remoción de arsénico (V) asitida por oxidación UV solar en un fotoreactor de sección circular", Investigacion \& desarrollo, 9, 58-79 (2009).

[7] Tapanes, S. H., "Luminoterapia: Radiaciones infrarrojas y ultravioletas" 2011, http://www.sid.cu/sitios/rehabilitación/temas.php?idv=916

[8] Betts, G. R., et al., "The effect of spectral variations on the performance parameters of single and double junction amorphous silicon solar cells", Solar Energy Materials \& Solar Cells, 85, 415-428 (2005).

[9] Hirata, Y., Tani, T., "Output variation of photovoltaic modules with environmental factors-I, The effect of spectral solar radiation on photovoltaic module output", Sol. Energy, 55, 463-468 (1995).

[10] Gottschalg, R., et al., "Experimental investigation of spectral effects on amorphous silicon devices in outdoor operation", Proceedings of the 29th IEEE Photovoltaic Specialists Conference, 1138-1141 (2002).

[11] Michael, S., Meyer, E. L., "The effects of spectral evaluation of c-Si modules", Progress in Photovoltaics: Research and Applications, 19(1), 1-10 (2011).

[12] Muller, M., et al., "Investigation into Spectral Parameters as they Impact CPV Module Performance", Procc 6th International Conference on Concentrating Photovoltaic Systems, 8, 5200-47959 (2010).

[13] Cebecauer, T., Suri, M., and Gueymard, C., "Uncertainty sources in satellite-derived direct normal irradiance: how can prediction accuracy be improved globally", Proc. SolarPACES Conj, 20-23 (2011).

[14] P. Derewonko, J.M. Pearce, Optimizing design of household scale hybrid solar photovoltaic combined heat and power systems for Ontario, 2009 34th IEEE Photovoltaic Specialists Conference PVSC, pp.1274-1279, 2009.

[15] Lucano, M., Fuentes, I., "Evaluación del potencial de radiación solar global en el departamento de Cochabamba utilizando modelos de sistemas de información geográfica e imágenes satelitales", Revista Boliviana de Física, $16,13-21$ (2010).

[16] Ngnyen, H. T., Pearce, J. M., "Estimating potential photovoltaic yield with r.sun and the open-source Geographical Resources Analysis Support System", Solar Energy, 84(5), 831-843 (2010).

[17] Derewonko, P., , J. M., "Optimizing design of household scale hybrid solar photovoltaic combined heat and power systems for Ontario", Proc. 34th IEEE Photovoltaic Specialists Conference PVSC, 1274-1279 (2009).

[18] Gueymard, C., Wiicox, S., "Assessment of spatial and temporal variability in the US solar resource from radiometric measurements and predictions from models using ground-based or satellite data", Solar Energy, 85( 5), 1068-1084 (2011). 